\section{EMT $-4,65$}

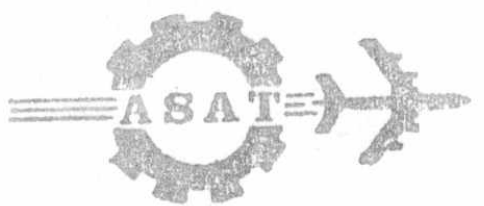

MILITARY TECHNICAL, COLLEGE

\title{
STATIC AIND DYNAMIC CHARACTERISTICS OF A CLASS OF PRESSURE COMPENSATED FLOW CONTROL VALVES
}

\author{
M. G RABIE ${ }^{*}$ S. A. KASSEM ${ }^{* *}$ \\ S. A. EL SAYED ${ }^{* * *}$ \\ H. M. YOUSIF ${ }^{* * * *}$
}

\section{ABSTRACT}

This paper deals with the static and dynamic characteristics of a pressure compensated flow control valve. A nonlinear mathematical model of the valve is developed. The simulation of the valve is carried out using a digital computer on the basis of the developed mathematical model. The validity of the models is verified in the steady state by comparing simulation and experimental results. The dynamic characteristics of the valve are predicted theoretically using the simulation program. The influence of some congtructional parameters on the valve 3 tatic and dynamic characteristics is investigated and optimum volues of these parameters are determined.

\section{NOMENCLATURE}

As Area of the $1^{\text {st }}$ damping orifice, $\mathrm{m}_{2}^{2}$.

As Area of the $2^{\text {nd }}$ damping orifice, $\mathrm{m}^{2}$,

Ap Spool area subjected to pressure. $\mathrm{m}^{2}$.

At Throttling area of the valve, $m$.

b Compensating stage opening, $m$.

B Bulk modulus, MPa.

Ce Contraction coefficient.

Cd Digcharge coefficient.

di $1^{\text {gl }}$ damping orifice diameter. $m$.

dz $2^{\text {nd }}$ damping orifice diameter. $m$.

dp Spool diameter, m.

$f$ Coefficient of viscous friction, $\mathrm{NS} / \mathrm{m}$.

$k \quad$ Spring stiffness, $N / m$.

m Spool and spring reduced mass, $\mathrm{kg}$.

$\mathrm{P}_{1}$ Input pressure, MPa.

$\mathrm{P}_{2}$ Pressure in the $1^{\text {st }}$ chamber. MPa.

$\mathrm{P}_{3}$ Pressure in the $2^{\text {nd }}$ chamber. $\mathrm{MPa}$.

* Assoc. Prof., Aeronautical Dept., M.T.C., Cairo.

* Prof. Dept. of Mech.Design and Prod.. Eng.Faculty, Cairo Univ. *** Assoc.Prof.. Dept of Mech. Design and Prod.. Eng. Faculty. Zagazig Univ. $* * * *$ Eng., Suez Canal Authority. 


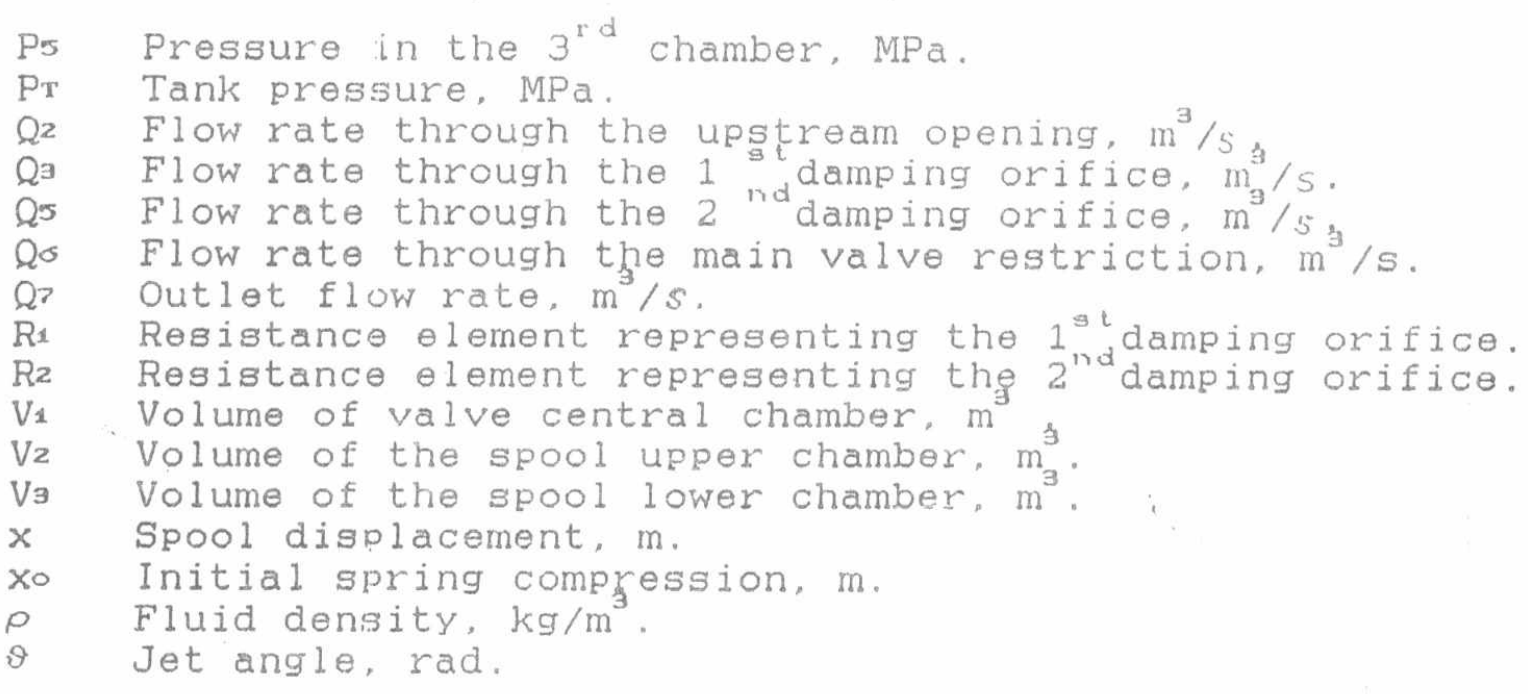

\section{INTRODUCTION}

The hydraulic power systems are widely applied for the control and power transmission in the different engineering fields. The control of the transmitted power and, consequently, the function of the controlled system is insured by the different hydraulic control valves. Among these valves one can distinguish the flow control valves, controlling the flow rates and the speeds of the moving organs. The investigation of the performance of these valves and their effect on the system behavior has been the subject of several publications. Takenaka and Urata [1] reported the results of a study of the dynamic characteristics of a pressure compensated flow control valve. Their study is based upon the develcpment of a linearized model of the valve. They reached concrete conclusions concerning the effect of pressure compensator and the valve transient behavior. In his survey of the studies of dynamic characteristics of the hydraulic control valves in Japari. Takinaka [2] pointed out the importance of the investigation of the valve stability and speed of response. Kassem and Rabie [3] deduced a nonlinear mathematical model of a flow control vilve with series pressure compensator. The model is based upon the development of an augmented bond graph of the valve. The valve dynamic behavior is investigated theoretically on the basis of this model. The study pointed out the important effect of the damping orifices on the valve transient response.

Herein, the performance of a two way series pressure compensated flow control valve with pressure compensator prior to the throttling section is investigated. The valve is assumed to be arranged in a neter out mode of speed control. A nonlinear mathematical model of the valve is deduced. Alternatively, a block bond graph is developed. The simulation is realized on a digital computer using TUTSIM program. The static characteristics of the valve are evaluated experimentally and theoretically while the valve transient response is investigated theoretically. The effect of some of the valve constructional and operational parameters on the response is investigated. 


\section{DESCRIPTION AND MODELLING OF THE FLOW CONTROL VALVE.}

The studied pressure compensated flow control valve is drawn schematically in Fig. 1. The valve consists of a pressure compensating stage prior to the throttle element. The pressure difference across the sharp edged throttling element acts on the spool of the pressure compensating stage against the action of a built in spring. The upper chamber of the spool is connected to that above the annular part of the spool by means of radial and axial holes. These holes, being of relatively large diameter, are found to be of negligible hydraulic resistance. The spool moves in the direction to compensate the effect of the pressure variation across the valve.

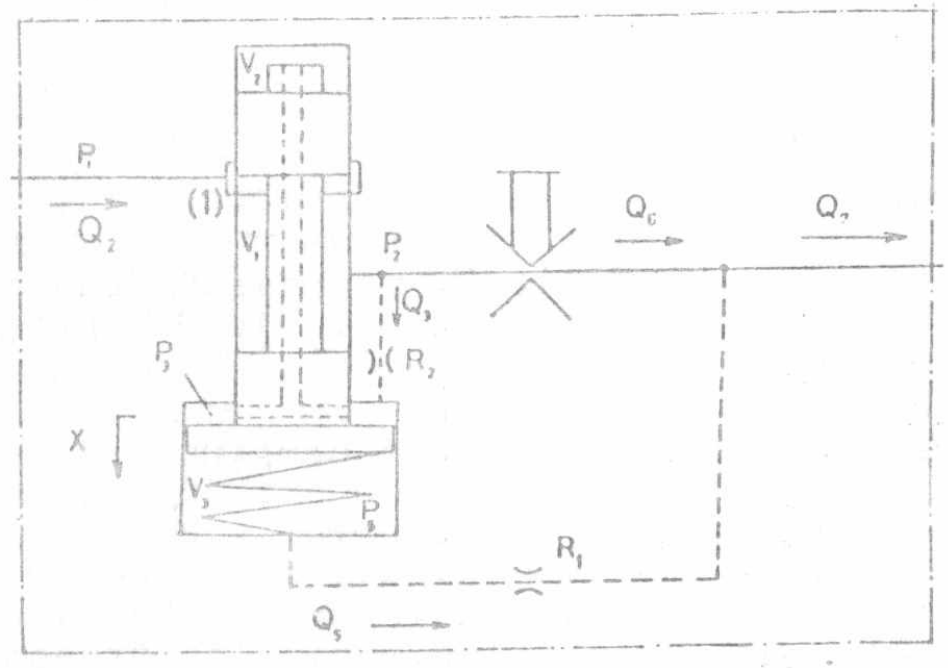

Fig. 1. Scheme of the series pressure compensated flow control valve

MATHEMATICAL MODEL

The studied flow control valve can be described mathematically by the following equations, considering the following assumptions:

1. The internal leakage through the spool radial clearance is negligible.

2. The valve is installed in a meter-out arrangement and its exit pressure is atmospheric.

3. The spool and main valve restrictions are of sharp edges.

$Q_{2}=C d r d p(b-x) \sqrt{\frac{2}{p}\left(P_{1}-P_{2}\right)}$

$Q_{\sigma}=C d A_{l} \sqrt{\frac{2}{\rho}\left(P_{2}\right)}$

$Q_{3}=C d 3 A_{3} \sqrt{\frac{2}{P}\left(P_{2}-P_{3}\right)}$

$Q s=\operatorname{Cds} A s \sqrt{\frac{2}{\rho}(P s)}$ 


$$
\begin{aligned}
& Q_{7}=Q_{5}+Q_{0} \\
& Q_{2}=Q_{3}+Q_{0}+\frac{V_{1}}{B} \frac{d P_{2}}{d t} \\
& Q_{3}=A_{p} \frac{d x}{d t}+\frac{V_{2}+A_{p} x}{B} \frac{d P_{3}}{d t} \\
& Q_{5}=A_{p} \frac{d x}{d t}-\frac{V_{3}-A_{p} x}{B} \frac{d P_{5}}{d t} \\
& A_{p}\left(P_{3}-P_{5}\right)-m \frac{d^{2} x}{d t^{2}}-f-\frac{d x}{d t}-k\left(x+x_{0}\right)+\frac{\rho Q^{2}}{C d \pi d p(b-x)}=0
\end{aligned}
$$

The term $(A p x)$ is found to be neglegible compared with $V z$ and $\mathrm{Va}$, in equations 7 and 8 ; therefore it is neglected.

\section{BOND GRAPH}

A bond graph model of the valve is developed, fig.2. The input pressure $P_{1}$ and exit pressure PT are imposed by the sources SE3 and SE31. The two port resistor $R_{4}$ represents the effect of the spool valve restriction. The effect of fluid compressibility in the valve chambers of volumes $V_{1}, V_{2}$ and $V_{3}$ is taken into consideration by the capacitors $\mathrm{C}$, $\mathrm{Cz}_{8}$ and $\mathrm{C}_{12}$ respectively. The energy dissipating effect of the damping orifices Ri and Rz and that of the main restriction is introduced by the resistances R3o, Ris and Rio respectively. The inertia element I10, the resistance Rzz and the capacitance Cz3 represent the effect of the inertia of the moving parts, the viscous friction resisting the spool motion and the spring stiffness respectiveiy.

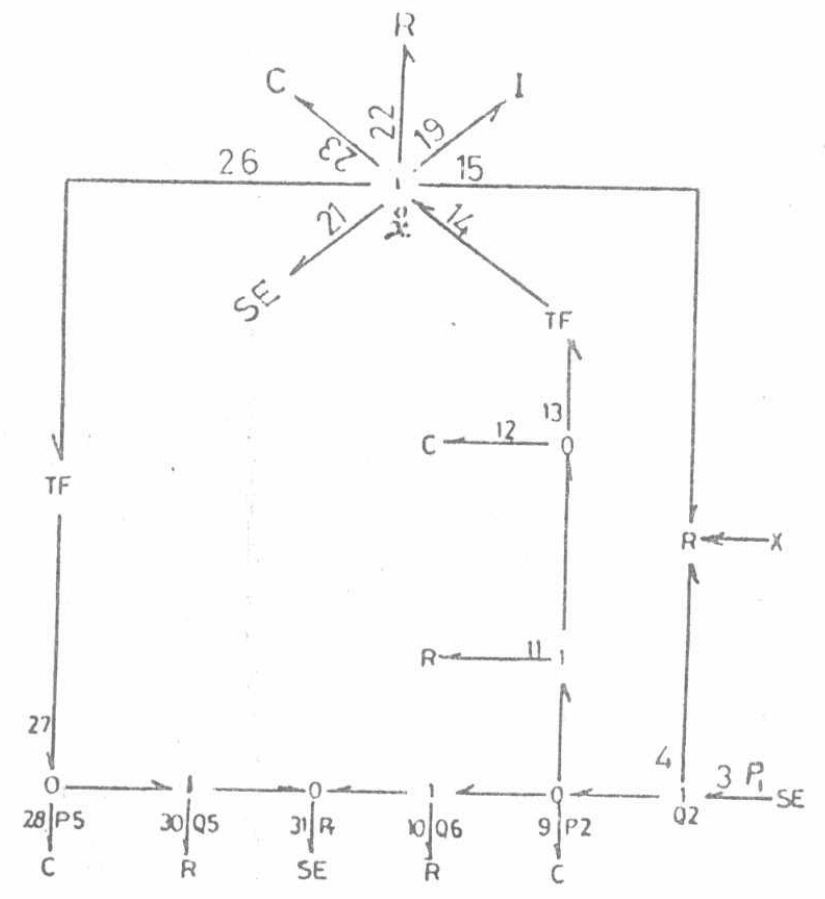

Fig.1. Bond graph.

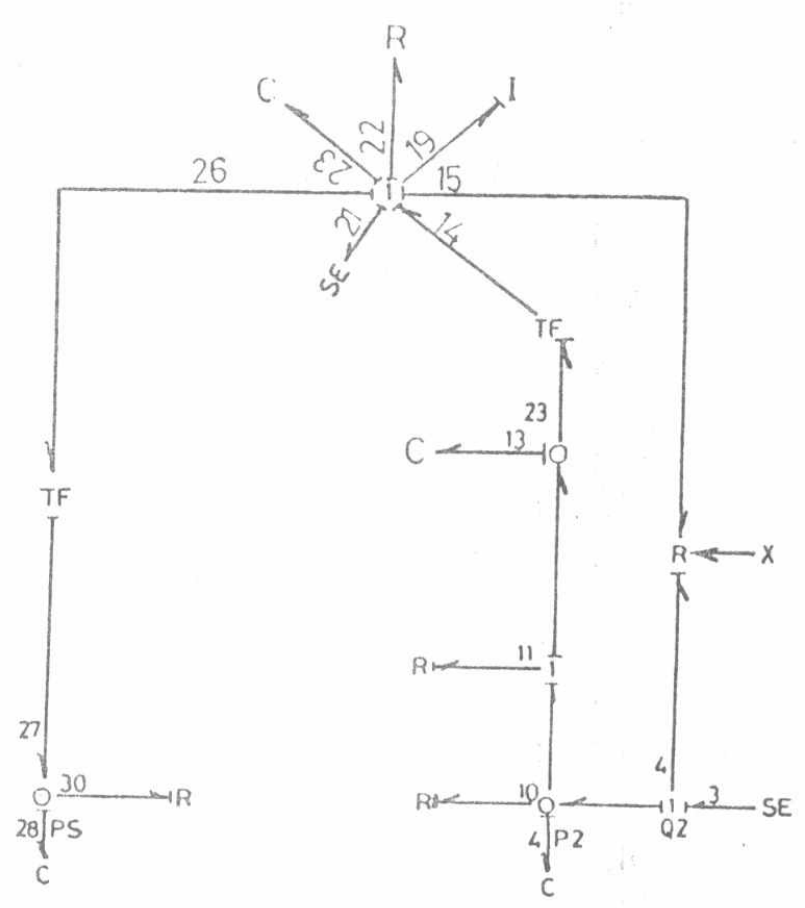

Fig. 3. Augmented bond graph. 


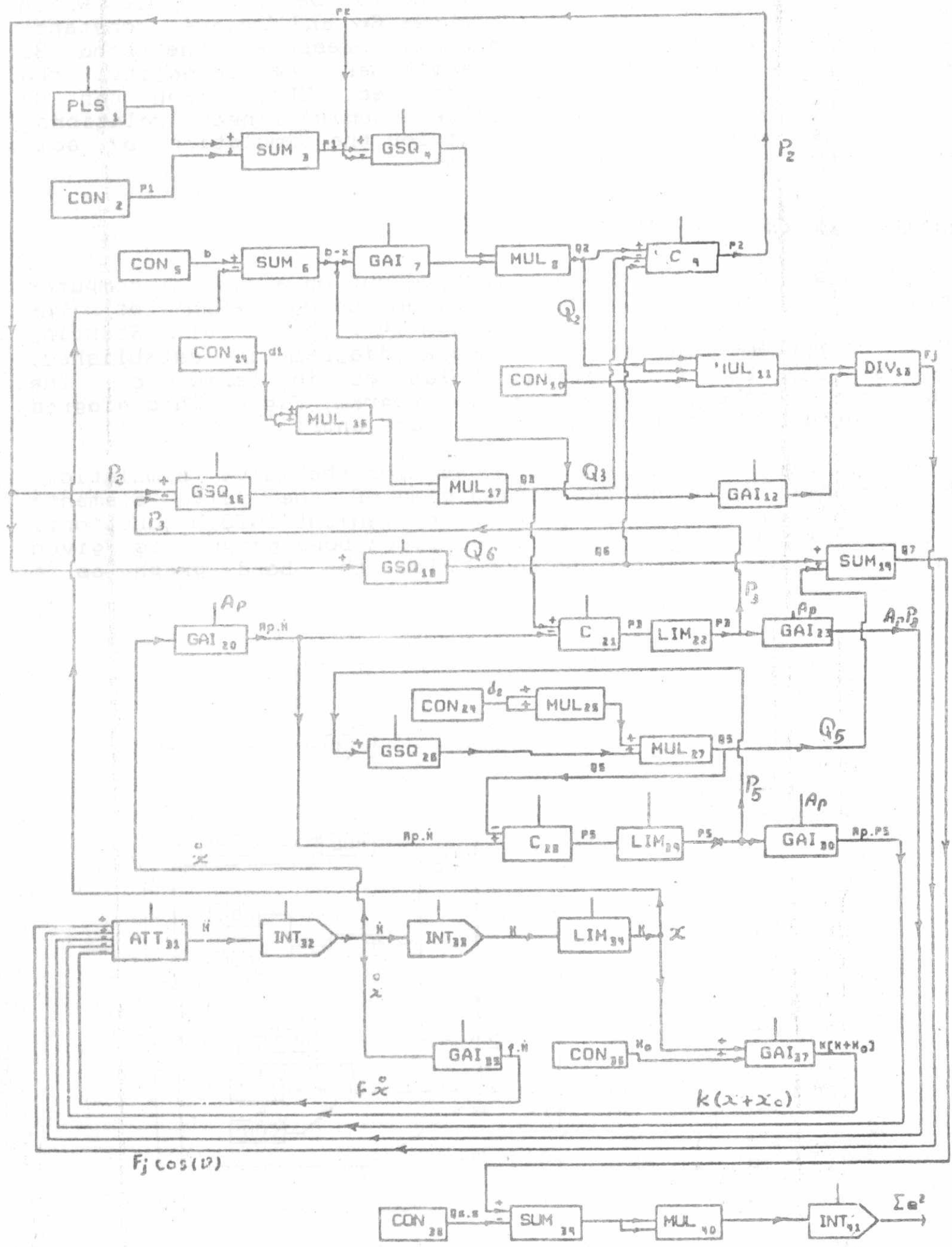

F1g. A. TUTSIM block diagram of the valve 
In this model, the variation of the volume of the spool chambers due to the spool displacement is found to be negligible which allows to assume that the capacitances Ciz and Cze are constant. Considering the assumption of zero exit pressure, the bond 31 can be eliminated. Then by the assignment of causality, the augmented bond graph of fig.3 is obtained. This graph can be used for the simulation of the valve assuming linear relations. It is accepted as a structure input for the simulation by some digital computer simulation programs.

\section{SIMULATION OF THE VALVE}

The simulation of the valve is carried out on a digital computer using the TUTSIM simulation program using each of the mathematical model and the bond graph [4], [5] \& [6]. Starting with the mathematical model, a block diagram is established, representing the mathematical relations in terms of the functional blocks of the simulation program, Fig.4. This diagram is accepted by the TUTSIM as a structure entry.

Alternatively, the bond graph is used for the valve simulation. The nonlinear relations describing some of the valve elements are introduced in the bond graph by convenient TUTSIM functional blocks. The resulting graph, called block bond graph, is given in Fig. 5, [7]. The TUTSIM accepts also the bond graph as a structure entry.

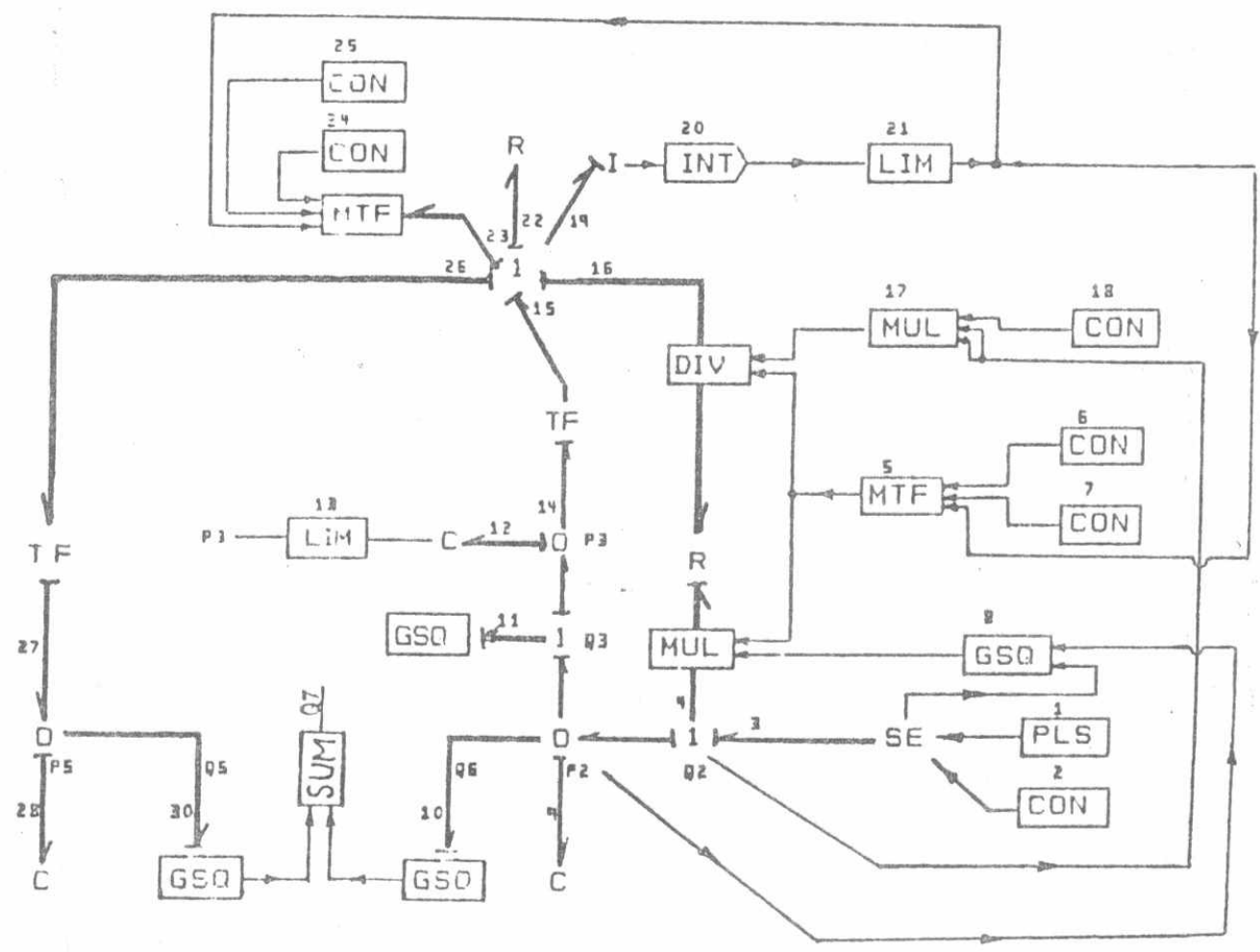

Fig. 5. Block bond graph of the flow control valve 
This study is applied to a series pressure compensated flow control valve type 2FRM size 10 produced by Rexroth. Germany. The parameters of this valve were found out from the manufacturers data sheets and by direct measurements on the valve elementg. The valve has the following parameters.

$$
\begin{array}{lll}
\mathrm{dp}=12 \mathrm{~mm} & \mathrm{~b}=5.5 \mathrm{~mm} & \text { Ap }=706.5 \mathrm{~mm}^{2} \\
\mathrm{k}=20 \mathrm{kN} / \mathrm{m} & \mathrm{x}_{0}=10^{\circ} \mathrm{mm} & \text { Al }=0 \text { to } 20 \mathrm{~mm}^{2}
\end{array}
$$

Two different simulation programs of the valve were developed on the basis of the mathematical model and the block bond graph. These two simulation programs gave identical results.

\section{YALVE STATIC CHARACTERISTICS}

The valve behavior in the steady state have been evaluated by finding out the relation betwoen the valve flow rate and the input pressure. Theoretically this relation is calculated by the simulation program for different values of valve restriction area At. The same dependence is evaluated experimentally. Fig. 6 carries the theoretical and experimental results. The figure shows remarkable agreement between the experimental and simulation results. It is obvious that there is a minimum value of the input pressure, in order to attain a. nearly constant low. This value is found to be about $0.5 \mathrm{MPa}$.

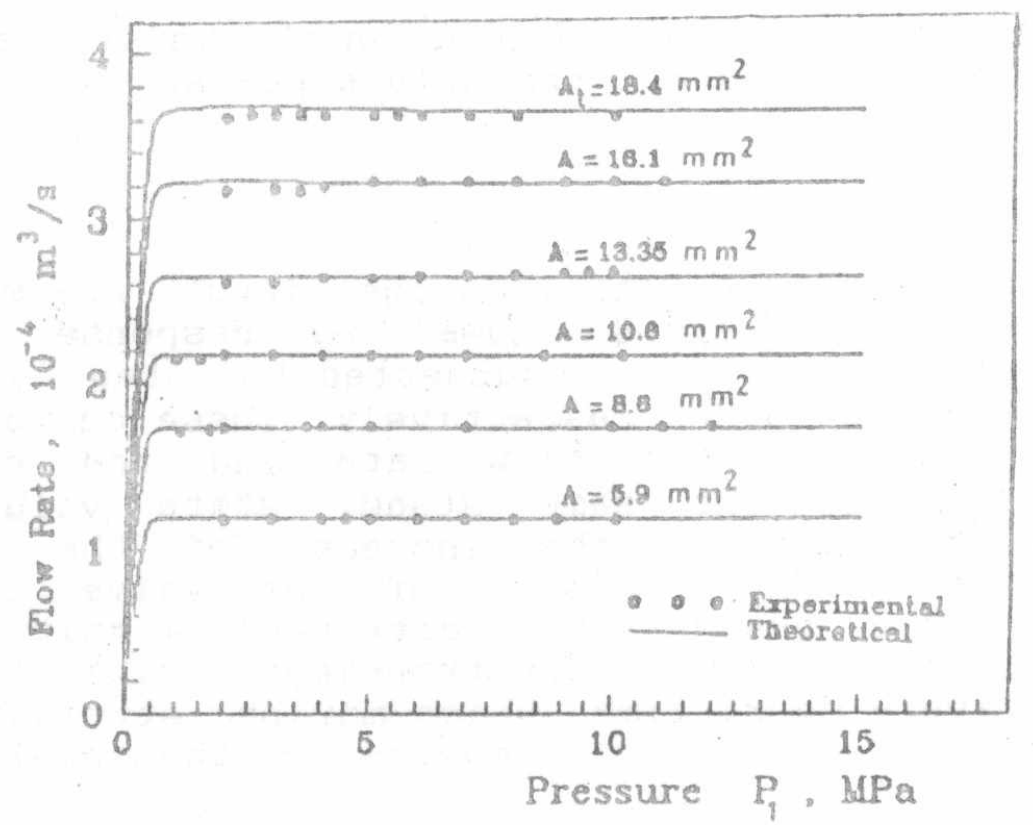

Fig. 6. Steady state relation between the valve flow and inlet pressure, for different throtting areas. 
The effect of the spring stiffness on the valve static characteristi::s is estimated by calculating the relation between the valve flow and input pressure for different values of the spring stiffness. The calculation results are given in figure 7 . The figure gives a nondimensional plot of the flow rate versus the input pressure. The reference flow $Q \mathrm{r}$ is the flow rate corresponding to a chosen throttle area, At, of $18.4 \mathrm{~mm}^{2}$, an input pressure of $5 \mathrm{MPa}$ and a spring stiffness of $20 \mathrm{kN} / \mathrm{m}$. The figure shows that the minimum pressure required to reach the constant flow rate increases with the spring stiffness.

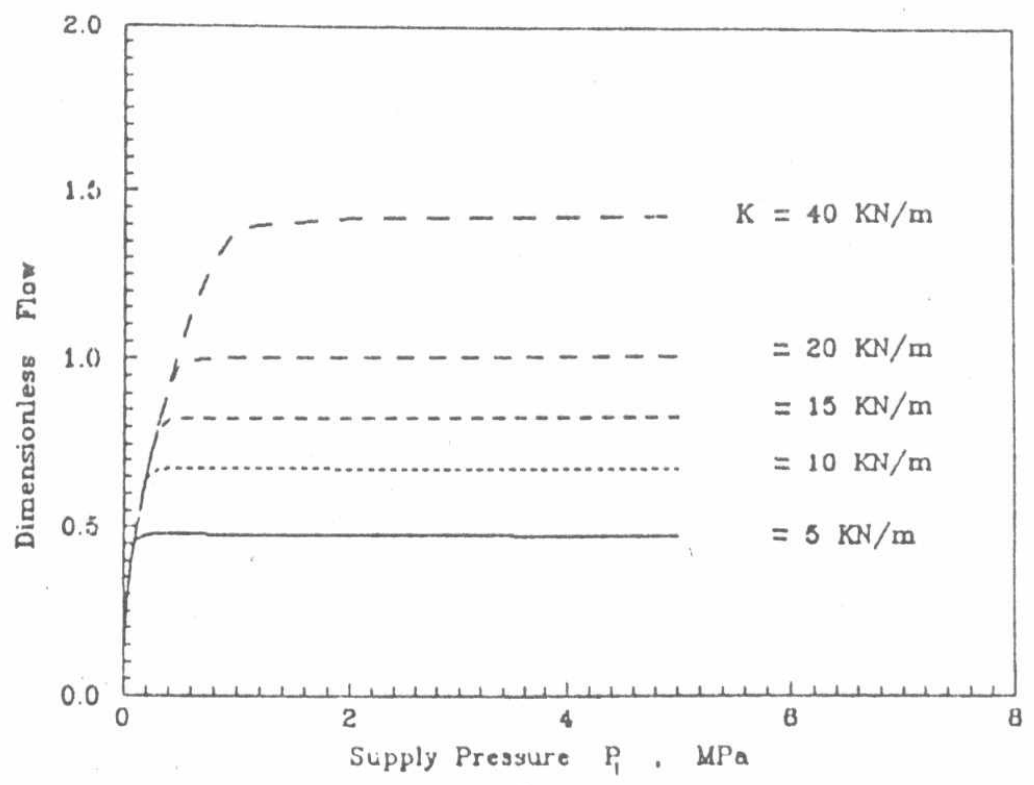

Fig. 7. Eflect of the spring stifness on the valve static characteristics, for constant throttle area; $A t=18.4 \mathrm{~mm}^{2}$

\section{VALVE DYNAMIC CHARACIERISIICS}

The valve response to step variation in the input pressure is investigated theoretically. Fig. 8 shows the response of the valve when the input pressure $P_{1}$ is subjected to step increase from $5 \mathrm{MPa}$ to $6,7.5$ and $10 \mathrm{MPa}$ respectively. These curves show considerable overshoots in the flow rate and the response decrease rapidly to almost the same steady state value. The maximum overshoot increases with the increase of the applied step pressure variation. The response of the valve to step reduction of the input pressure of different magnitudes is calculated and plotted in Fig. 9. The transient period is seen to exhibit a relatively short time, which may be attributed to to the very small spool displacement covered by the spool in the transient period as shown in Fig. 10.

The valve includes two damping orifices. These orifices are to be sized to give the best transient behavior, according to a selected criterion. 


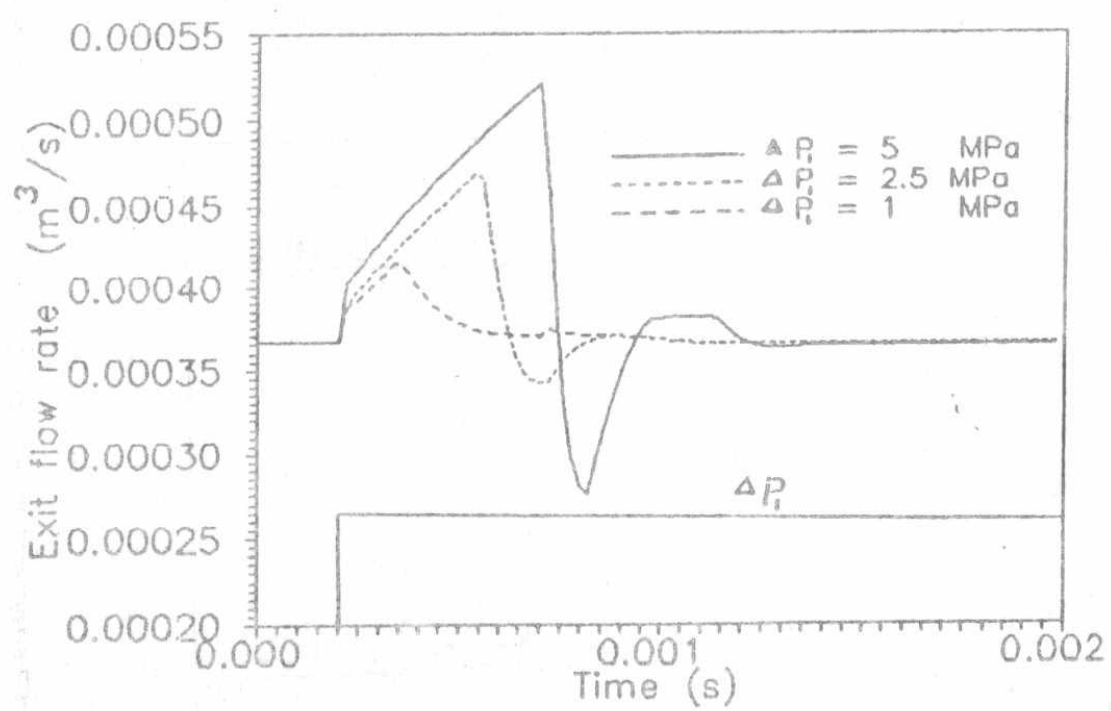

Fig. B. Trangient response of the valve exit flok rate to step increase of input pressure of different magnitudos.

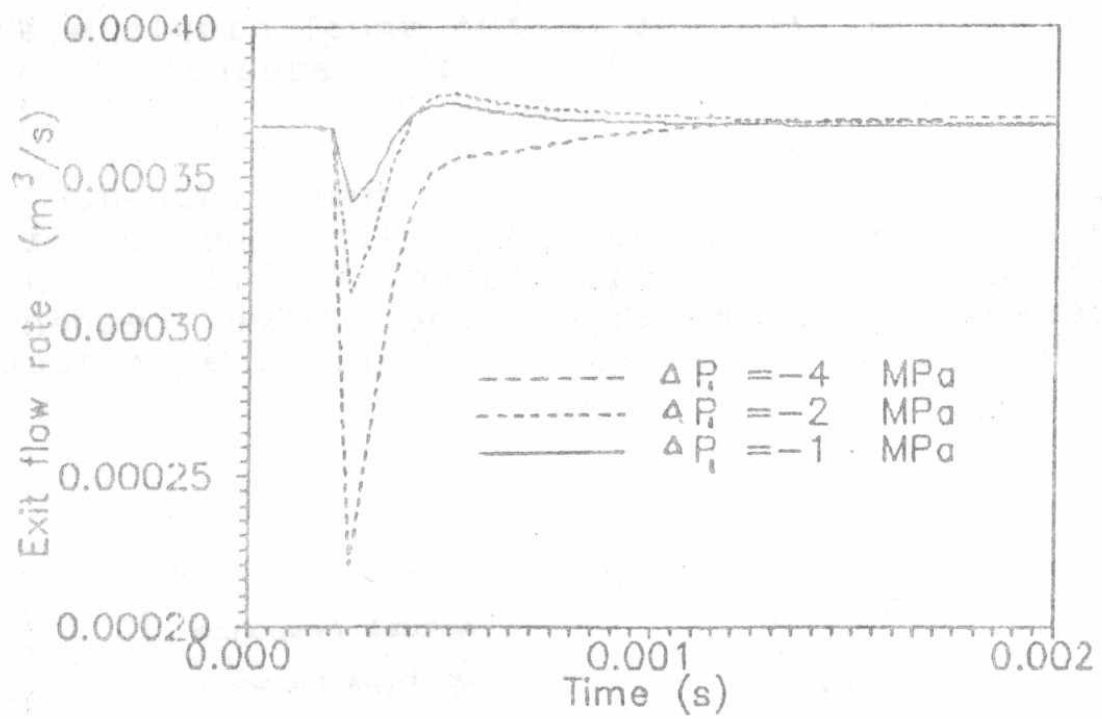

Fig. 9. Transient response of the valve exit flow rate to step decrease of input pressure of different magnitudeg.

The used simulation program gives the possibility of parameter estimation using the simplex method. Up to eight parameterg can be estimated to give the minimum value of the selected error function. Using the parameter estimation command, PE, the optimum diameters of the damping orifices could be predicted. minimizing the integral square error IES of the response, where:

$$
I E S=\int\left(Q_{7}-Q_{93}\right)^{2} d t
$$

The optimum values of these diameters are found to be:

$$
\mathrm{d}_{1}=5.9 \mathrm{~mm} \text { and } \mathrm{dz}=1.2 \mathrm{~mm}
$$




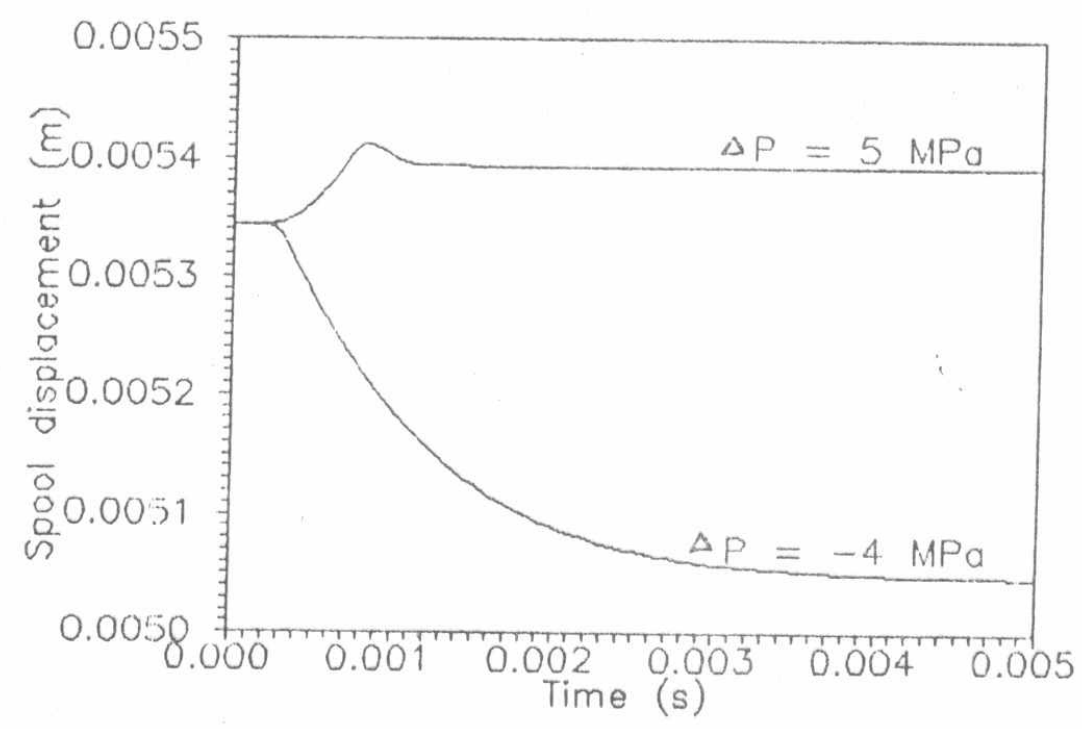

Fig.10. Transient response of the spool displacement to step variation of input pressure.

The transient response of the valve to step increase of the inlet pressure by $10 \mathrm{MPa}$, when equipped with the original and with the proposed orifices, is calculated, fig 11. This figure shows a considerable improvement of the valve response when equipped with the optimum orifices, specially the reduction of the maximum over shoot.

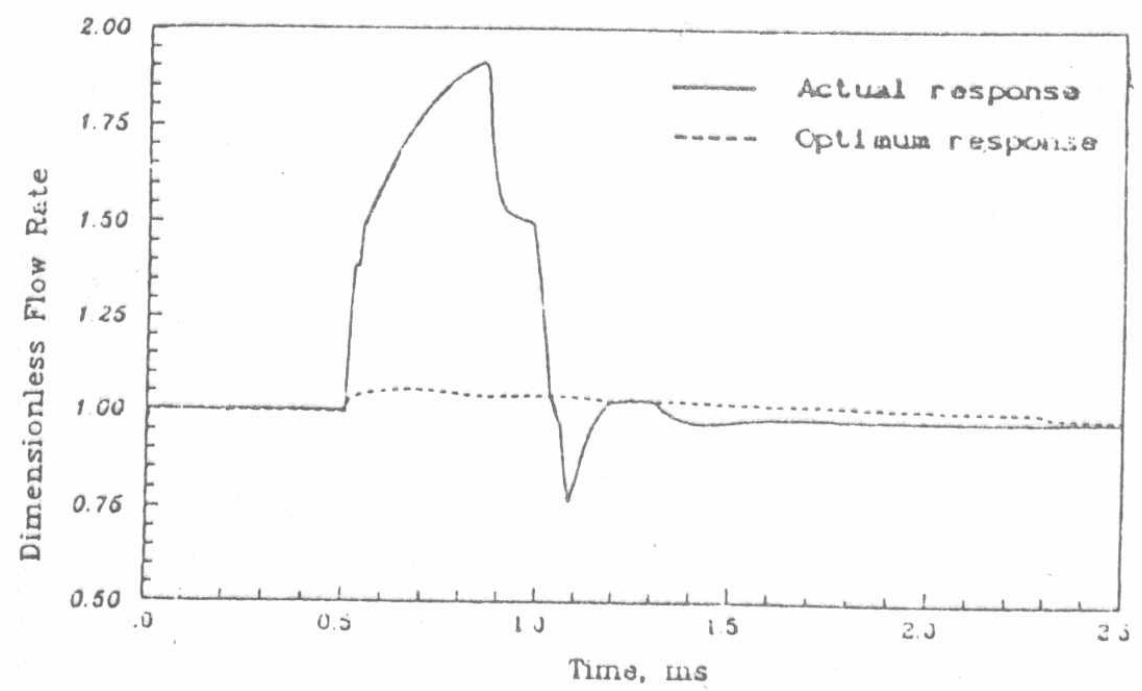

Fig.11. Effact of the optimum damping orifices on the valve transient response, keeping $A_{t}=18.4 \mathrm{~mm}^{2}$ and applying a step increase in the inlet pressure of $10 \mathrm{MPa}$. 


\section{CONCLUSION} The performance of a series pressure compensated flo: control
valve is investigated in this work. A nonlinear mathematical model of the valve is deduced. Alternatively a block bond graph is developed. The computer simulation of the valve is carried out using the TUTSIM simulation program. The simulation results gave good agreement with the experimentar restitio behavior is of the static characteristics. The valve very short time of studied theoretically. The valve probents flow over shoots. The response associated by consider, on the basis of simulation transient response can be improming orifices cianeters. The results, by changing these orifices are determined using the optimum dimensions of these orifices are the simulation program.

\section{REFERENCES}

(1) Takemaka T.and Urata Eo, "Static and Dynamic Charactoristicg of Oll Hydraulic Control Valve". Fluid Power International Conference. London sept.. 1969. the Studies of Dynamic

[2] Takenaka To, "A Survey of tho of Oil Hydraulic Control Values in Japan", Characteristics of Oil Hydraulic Control, pol.1. 1235- 1242. Flow Meisurement and Contromerica, Pjttsburgh, Pa, 1974.

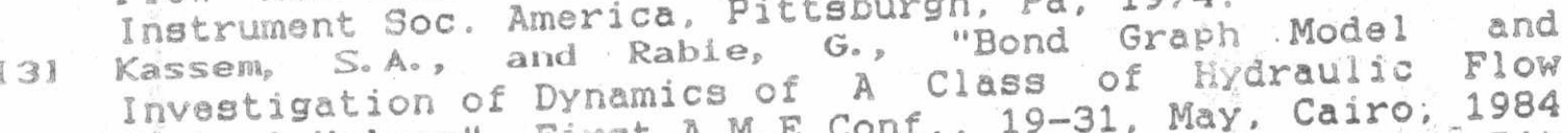
Control Valves". Firgt A.M.E Conf.. 19-31. May, Cairo, 1984.

4. Meerman et al, "TUTSIM Interactive Simulation on 8 Bit Personal Computer", 10 Imacs Con. Montreal. Automation, tho

[5] Meerman, J.W, "TUTSIM User Manual" will am Ho Murray "Mathematical Modeling with TUTSIM". PC

[61 Will am H. Murray "Math. Jolirnal, July, 1984 .
171 M.G. Rabie, SA. Kassem, S.A. Elsayed, Mo A. Aziz and O.G.
Elsayed, "Block Bond Graph and TUTSIM. A Powerful Tool for Nonlinear Dynamic Systems Modeling and Simulation" Alox. Eng. J., Alex. Univ., Volume 28 No.3. pp. 519-537. 1989. 